\title{
Analisa Perhitungan Pulley dan V-Belt Pada Sistem Transmisi Mesin Pencacah
}

\author{
Haris Mahmudi ${ }^{1)}$ \\ ${ }^{1)}$ Program Studi teknik Mesin, Universitas Nusantara PGRI Kediri \\ E-mail: ${ }^{1}$ harismahmudi@ unpkediri.ac.id
}

\begin{abstract}
Abstrak
Pengembangan mesin yang dirancang dalam penelitian ini menggunakan penggerak (transmisi) berupa perpaduan pulley dan v-belt. Alasan menggunakan sistem penggerak berupa pulley dan $v$-belt adalah dirasa lebih mudah dan efisien dalam proses pengerjaannya. Tujuan dari penelitian ini adalah untuk menganalisa hitungan ukuran pulley dan v-belt yang cocok untuk mesin pencacah yang telah dikembangkan. Penelitian ini menggunakan metode eksperimental desain, yaitu melakukan pengukuran, pengamatan dan perhitungan terhadap spesifikasi teknis dari mesin, kemudian menganalisis data tersebut sehingga memperoleh gambaran mengenai kinerja mesin yang pada akhirnya dapat memberikan gambaran tentang kelayakan mesin. Hasil penelitian diperoleh: : (1) ukuran pulley berdiamaeter 90 mm dan $180 \mathrm{~mm}$ dengan bahan dari baja ST37. (2) Panjang v-belt yang dibutuhkan $=1.333,95 \mathrm{~mm}$. (3) Jarak sumbu poros $v$-belt $=609,23 \mathrm{~mm}$. (4) Kecepatan keliling pulley penggerak $\mathrm{v}_{\mathrm{P}}=13,18 \mathrm{~m} / \mathrm{s}$. (5) Gaya keliling yang timbul $\mathrm{F}_{\text {rate }}=108,34 \mathrm{~N}$.
\end{abstract}

Kata Kunci: pulley, Transmisi, v-belt

\begin{abstract}
The development of the engine designed in this study uses a drive (transmission) in the form of a combination of pulley and $v$-belt. The reason for using a drive system in the form of a pulley and a v-belt is that it is easier and more efficient in the process. The purpose of this study is to analyze the size of the pulley and v-belt that are suitable for the chopper machine that has been developed. This study uses an experimental design method, namely measuring, observing and calculating the technical specifications of the machine, then analyzing the data so as to obtain an overview of the machine's performance which in the end can provide an overview of the feasibility of the machine. the results obtained: (1) pulley sizes $90 \mathrm{~mm}$ and 180 mm diameter with ST37 steel material. (2) The length of the required $v$-belt $=1333.95$ $\mathrm{mm}$. (3) V-belt axis distance $=609.23 \mathrm{~mm}$. (4) Circular speed of the driving pulley $v P$ $=13.18 \mathrm{~m} / \mathrm{s}$. (5) Circular force that arises Frate $=108.34 \mathrm{~N}$.
\end{abstract}

Keywords: pulley, transmission, v-belt

\section{PENDAHULUAN}

Peralatan manual dalam berbagai bidang pada pengerjaan yang membutuhakan waktu yang cukup lama, sehingga akan menimbulkan kejenuhan baik pada para pekerja maupun produsen itu sendiri, oleh karena itu pengerjaan dengan cara manual sekarang ini mulai ditinggalkan. modifikasi-modifikasi alat yang dulunya manggunakan manual lambat laun berpindah semi otomatis bahkan ada yang sudah otomatis. teknologi yang berkembang ini dipengaruhi oleh faktor-faktor tuntutan pasar dan sifat konsumen yang cenderung tidak bisa menunggu lama. Pengembangan teknologi pada dasarnya adalah untuk lebih memudahkan 
pekerjaan dan meningkatkan efisiensi peralatan, baik peralatan yang telah ada maupun peralatan yang akan dirancang (direncanakan). Teknologi juga bertujuan untuk dimanfaatkan pada saat ini maupun mendatang.

Perkembangan teknologi modern saat ini sangat impresif, yang dulunya menggunakan tenaga manusia/manual, hingga berganti dengan mesin Teknologi yang dikembangkan dalam penelitian perancangan ini adalah merancang suatu mesin pencacah daun kering. Fungsi daun kering ini adalah sebagai pupuk alami (organik). Pupuk organik berfungsi untuk memperbaiki sifat fisik dan struktur tanah. Pupuk organik berguna untuk memperkaya unsur hara, bahan organik tanah, dan memperbaiki sifat fisik, kimia dan biologi tanah [1].

Daun kering merupakan salah satu jenis sampah yang biasanya tidak digunakan lagi oleh orang. Biasanya sampah daun kering dibuang begitu saja atau dibakar. Tapi jika dapat memanfaatkan sampah ini, maka akan berguna. Menurut [2], Sampah adalah barang yang dianggap sudah tidak terpakai dan dibuang oleh pemilik/pemakai sebelumnya, tetapi bagi sebagian orang masih bisa dipakai jika dikelola dengan prosedur yang benar. Sampah sebagai barang yang masih bisa digunakan harus dapat dimanfaatkan sebagai bahan mentah atau bahan yang berguna lainnya. Produk hasil perancangan ini bertujuan untuk mengasilkan mesin pencacah daun kering yang dapat mengoptimalkan kebutuhan konsumsi pupuk terutama pupuk alami. Daun kering dipilih karena mudah didapatkan dan menjadi bagian terbesar sampah yang ada disekitar kita.

Pengembangan mesin yang dirancang dalam penelitian ini menggunakan penggerak (transmisi) berupa perpaduan pulley dan v-belt. Alasan menggunakan sistem penggerak berupa pulley dan v-belt adalah dirasa lebih mudah dan efisien dalam proses pengerjaannya. Adapun penelitian terdahulu yang mendukung penelitian perancangan ini adalah Mesin penyuwir daging yang merupakan alat bantu dalam proses penyuwiran daging menjadi suiran-suiran tipis yang akan menjadi abon [3]. Penelitian tersebut juga menggunakan sistem transmisi berupa pulley dan v-belt. Selanjutnya mesin pencacah tongkol jagung [4], yang bertujuan untuk mencari tingkat efisiensi dari diameter pulley pada sistem transmisinya. Bentuk pulley dan belt adalah sejajar dengan porosnya dan dapat digunakan untuk memindahkan daya motor dengan putaran yang tetap atau berubah-ubah, untuk merencanakan yang perlu diperhatikan adalah sebagai berikut: (1) Daya yang dipindahkan, (2) Jumlah putaran permenit, (3) Diameter pulley.

Sistem transmisi yang digunakan dalam penelitian perancangan ini adalah menggunakan pulley dan v-belt. Sedangkan desain dari pulley dan v-belt terdapat dalam Gambar 1 sebagai berikut.

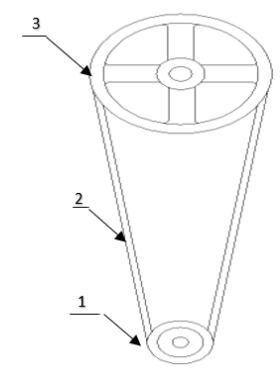

Gambar 1. Desain alat perancangan 
Keterangan : 1. Pulley A (pada Poros)

2. v-belt

3. Pulley B (pada engine)

Keuntungan dari mesin yang menggunakan pulley dan v-belt ini adalah tidak menimbulkan suara berisik, biaya perawatan yang relatif lebih murah dibandingkan dengan penggerak yang menggunakan gear dan rantai, sedangkan kerugian yaitu tenaga yang dihasilkan tidak begitu kuat seperti menggunakan tranmisi dengan roda gigi. v-belt terbuat dari karet yang dirancang sedemikian rupa hingga penampang membentuk trapesium. Dari latarbelakang diatas, maka tujuan dari penelitian ini adalah Tujuan dari penelitian ini adalah untuk menganalisa hitungan ukuran pulley dan v-belt yang cocok untuk mesin pencacah yang telah dikembangkan.

\section{METODE PENELITIAN}

Metode penelitian yang digunakan adalah metode eksperimental desain, yaitu melakukan pengukuran, pengamatan dan perhitungan terhadap spesifikasi mesin, kemudian menganalisis data tersebut sehingga memperoleh gambaran mengenai kinerja mesin yang pada akhirnya dapat memberikan gambaran tentang kelayakan mesin, yaitu mesin pencacah daun kering.

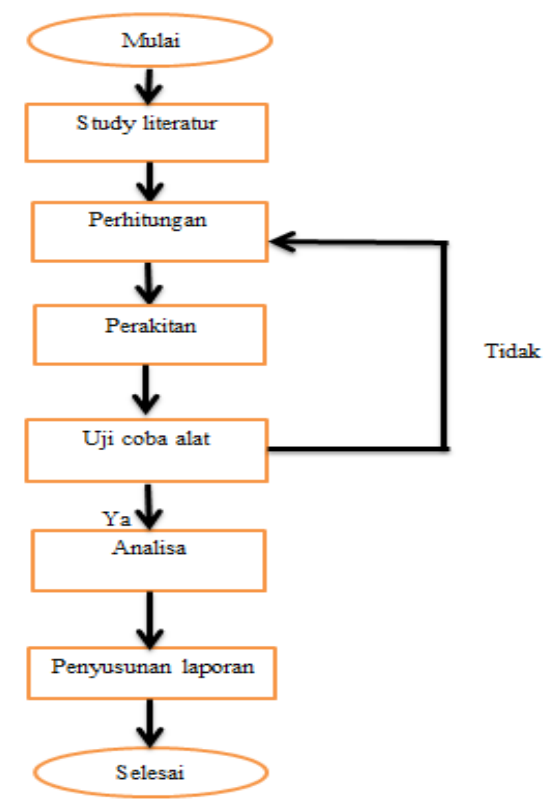

Gambar 2. Prosedur penelitian

Fokus dari penelitian ini adalah dalam tahapan untuk menganalisa hasil hitungan komponen utama dari suatu mesin pencacah yang telah dikembangkan sebelumnya. Adapun rancangan alat, pemilihan bahan dan ukuran-ukuran rangka mesin telah dilakukan dalam penelitian pengembangan sebelumnya. 


\section{HASIL DAN PEMBAHASAN}

\subsection{Desain Alat}

Pada alat pencacah daun kering terdapat komponen transmisi yang memiliki fungsi yang saling berhubungan. Adapun fungsi dari masing-masing komponen adalah sebagai berikut:

1. Pulley berfungsi untuk mentransmisikan daya dari penggerak menuju komponen yang digerakan dan mempercepat putaran.

2. V-Belt berfungsi untuk meneruskan putaran pulley B (engine) menuju pulley A (poros).

Proses kerjanya dari putaran motor menuju pulley B diteruskan menuju pulley A yang langsung berhubungan dengan poros. Untuk kerja v-belt hanya menghubungkan kedua pulley tersebut agar dapat berjalan secara bergantian. Bahan dari v-belt ini terbuat dari material karet, cord, rubber, dan canvas dengan ukuran tebal $12 \mathrm{~mm}$. Gambar 3 menunjukkan belt yang digunakan dalam penelitian perancangan ini.

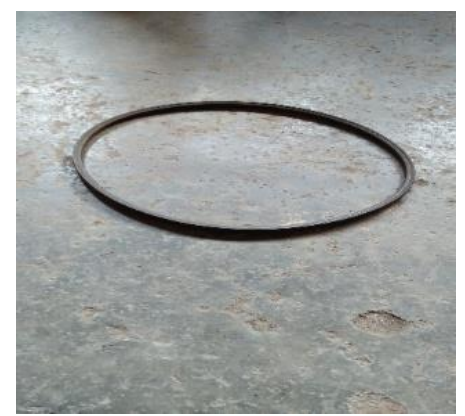

Gambar 3. Belt yang digunakan

Sedangkan untuk pulley yang digunakan dalam penelitian perancangan ini menggunakan bahan besi ST 37 dengan diameter pulley A (yang terhubung dengan poros) sebesar $15 \mathrm{~mm}$. diameter pulley $\mathrm{B}$ (yang terhubung dengan engine) sebesar $9 \mathrm{~mm}$. gambar 4 menunjukkan pulley yang digunakan.
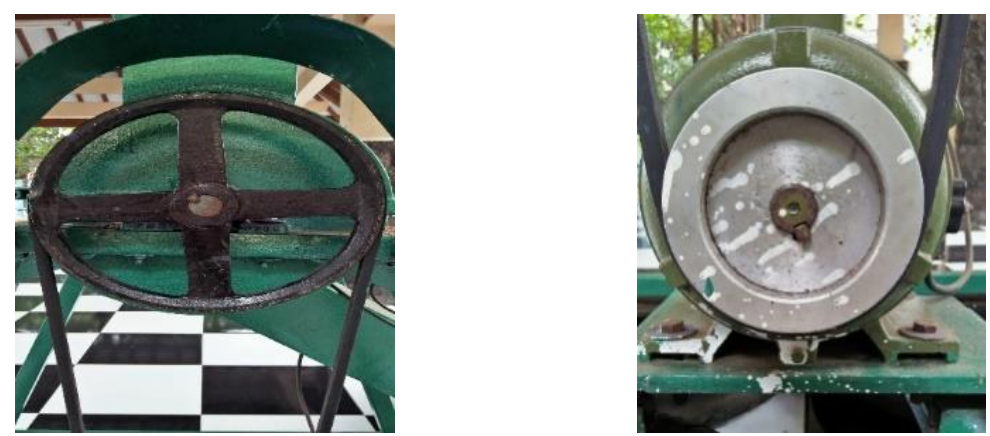

Gambar 4. (a) pulley A, (b) pulley B

Gambar 4 (a) merupakan pulley yang terhubung dengan poros, sedangkan Gambar 4 (b) merupakan pulley yang terhubung dengan engine. 


\subsection{Perhitungan}

Dalam merancang suatu alat, hal yang perlu diperhatikan adalah perhitungan alat dan bahan serta perhitungan output yang dihasilkan agar dapat diketahui optimalisasi dan efisiensi dari alat yang dirancang. Beberapa perhitungan dalam penelitian perancangan ini terdiri dari:

1. Daya motor yang dibutuhkan

Perhitungan daya motor yang dibutuhkan dalam mesin ini dapat diperoleh sebagai berikut:

a) Mencari putaran motor

$$
\begin{aligned}
& N=(f \times 120): P \\
& N=(45 \times 120): 4 \\
& N=56000: 4 \\
& N=1400 \text { Rpm }
\end{aligned}
$$

b) Mencari daya yang dibutuhkan

$$
\begin{aligned}
& \mathrm{P}=(525,2 \times 1400): 5252 \\
& \mathrm{P}=735280: 5252 \\
& \mathrm{P}=140 \mathrm{HP}
\end{aligned}
$$

Jadi daya yang dibutuhkan motor adalah $140 \mathrm{HP}$

2. Perhitungan pulley

Menghitung diameter pulley pada poros dengan mengasumsikan diameter pulley motor $\left(\mathrm{dp}_{\mathrm{A}}\right)$ bernilai $90 \mathrm{~mm}$ dan putaran motornya sebesar $1400 \mathrm{rpm}$. Sedangkan putaran pulley yang diinginkan adalah sebesar $800 \mathrm{rpm}$.

$$
\begin{aligned}
\operatorname{Dp}_{B} & =\frac{n_{1}}{n_{2}} \cdot d p_{A} \\
& =\frac{1400}{800} \cdot 90 \\
& =180 \mathrm{~mm}
\end{aligned}
$$

\section{Perhitungan V-Belt}

Sabuk yang digunakan untuk mentransmisikan putaran dari pulley motor atau pulley A ke pulley B pada perancangan mesin ini adalan jenis sabuk-V pemilihan sabuk tersebut bertujuan untuk memperkecil terjadinya slip pada saat mentransmisikan daya dan putaran.

Data yang diketahui adalah:

Diameter pulley motor (dp1) :15 mm

Putaran pulley penggerak $\left(n_{1}\right): 1400 \mathrm{put} / \mathrm{menit}$

Diameter pulley (dp2) : $9 \mathrm{~mm}$

Jarak antara sumbu poros pulley A pada sumbu poros pulley B (c) : $600 \mathrm{~mm}$

a) Panjang sabuk-V yang dibutuhkan (L):

$$
\begin{aligned}
L & =2 . c+\left[\left(d_{\text {pull } 2}+d_{\text {pull1 } 1}\right) \frac{\pi}{2}\right]+\left[\frac{\left(d_{\text {pull } 2}-d_{\text {pull1 } 1}\right)^{2}}{4 a}\right] \\
& \left.=2 \times 600+\left[(90+150) \cdot \frac{3,14}{2}\right)\right]+\left[\frac{(150-90)^{2}}{4 \times 600}\right] \\
& =1.333,95
\end{aligned}
$$


Panjang sabuk 1.333,95 (mm) tidak terdapat di pasaran, dari tabel panjang sabuk standar. Ukuran yang mendekati perhitungan di atas adalah dengan ukuran $1330(\mathrm{~mm})$.

b) Jarak sumbu poros sabuk-V

$$
\begin{aligned}
\mathrm{b} & =2 \mathrm{~L}-3,14(\mathrm{dp} 2+\mathrm{Dp} 1) \\
& =2.1330-3,14(150+90) \\
& =2896,86 \mathrm{~mm}
\end{aligned}
$$

Maka :

$$
\begin{aligned}
C & =\frac{b+\sqrt{b^{2}-8\left(D_{p}-d_{p}\right)^{2}}}{8} \\
C & =\frac{2896,86+\sqrt{2896,86^{2}-8(15-9)}}{8} \\
& =609,23 \mathrm{~mm}
\end{aligned}
$$

c) Kecepatan keliling pulley penggerak $V_{\text {pull }}$

$$
\begin{aligned}
v_{p} & =\frac{\pi \cdot d_{\text {pulley } . n_{\text {input }}}}{1000 \cdot 60} \\
v_{p} & =\frac{3.14 \cdot 180.1400}{1000.60} \\
v_{p} & =\frac{791280}{60000} \\
& =13,18 \mathrm{~m} / \mathrm{s}
\end{aligned}
$$

d) Gaya keliling yang timbul, $F_{\text {rate }}(\mathrm{kg})$

$$
\begin{aligned}
F_{\text {rate }}=\frac{(102 . N)}{v_{\text {pull }}} & \\
F_{\text {rated }} & =\frac{(102.14)}{13,18} \\
& =108,34 \mathrm{Kg}
\end{aligned}
$$

e) Gaya sisi Tarik

Gaya ini untuk memutar pulley

$F_{1}=F e \frac{e^{\mu^{\theta}}}{e^{\mu^{\theta}}}$

Dimana :

$\mathrm{e}=$ Bil. Exponet $\quad=2.7183$

$\mu=$ koefisien gesek $=0.28$

$\theta=$ sudut kontak pulley $=173,56^{\circ}$

f) Gaya sisi kendor

$$
\begin{aligned}
F_{2} & =F_{1}-\mathrm{Fe} \\
& =6,589-6,55 \\
& =0,039 \mathrm{~kg}
\end{aligned}
$$


g) Jumlah sabuk yang dipakai

$$
\begin{aligned}
& \mathrm{N}=\frac{p d}{p o \cdot k_{o}} \\
& \text { Dimana : } \\
& k_{o}=\text { factor koreksi }=0,99 \\
& \qquad p o=\frac{F e \cdot v}{102} \\
& =\frac{10,908.7,2}{102}=0,77 \mathrm{~kW}
\end{aligned}
$$

Maka :

$$
\begin{aligned}
\mathrm{N} & =\frac{1,76}{0,77 \times 0,99} \\
& =0,808 \rightarrow \text { satu buah }
\end{aligned}
$$

\section{KESIMPULAN}

Penelitian perancangan sistem transmisi menggunakan pulley dan $v$-belt pada mesin pencacah daun kering ini diperoleh beberapa kesimpulan sebagai berikut:

1. Produk berupa sistem transmisi menggunakan pulley dan $v$-belt pada mesin pencacah daun kering dengan spesifikasi alat sebagai berikut:

a. Ukuran pulley berdiamaeter $90 \mathrm{~mm}$ dan $180 \mathrm{~mm}$ dengan bahan dari baja ST37

b. v-belt terbuat dari material karet, cord, rubber, dan canvas dengan ukuran tebal $12 \mathrm{~mm}$

2. Panjang $v$-belt yang dibutuhkan $=1.333,95 \mathrm{~mm}$

3. Jarak sumbu poros $v$-belt $=609,23 \mathrm{~mm}$

4. Kecepatan keliling pulley penggerak $\mathrm{v}_{\mathrm{P}}=13,18 \mathrm{~m} / \mathrm{s}$.

5. Gaya keliling yang timbul $F_{\text {rate }}=108,34 \mathrm{~N}$.

\section{DAFTAR PUSTAKA}

[1] Bouajila, K. dan M. Sanna. 2011. Effects of Organic Amendments on Soil Physico-Chemical and Biological Properties. Journal Mater Journal of Materials and Environtmental Science, Vol 2 (S1).

[2] Nugroho, 2013. Sampah Organik. PT. ARGO Tunas Teknik. Surabaya

[3] Setiawan D . (2018). Rancang Bangun Mesin Penyuwir Daging Untuk Bahan Baku Abon. JITM. Vol.10 Akademi Teknik soroako

[4] Iswahyudi R . (2018). Perancangan Transmisi Daya Pada Mesin Pencacah Tongkol Jagung Kapasitas 100kg/Jam Dengan Sistem Puli Dan V-Belt. Kediri. Universitas Nusantara PGRI Kediri 